\title{
Novos táxons de Hemilophini (Coleoptera, Cerambycidae, Lamiinae) sem carenas nos élitros da Região Neotropical
}

\author{
Maria Helena M. Galileo ${ }^{1,3}$ \& Ubirajara R. Martins ${ }^{2,3}$
}

\begin{abstract}
${ }^{1}$ Museu de Ciências Naturais, Fundação Zoobotânica do Rio Grande do Sul. Caixa Postal 1188, 90001-970 Porto Alegre-RS, Brasil. ${ }^{2}$ Museu de Zoologia, Universidade de São Paulo. Caixa Postal 42494, 04218-970 São Paulo-SP, Brasil.

${ }^{3}$ Bolsista do CNPq.
\end{abstract}

\begin{abstract}
New taxa in Hemilophini (Coleoptera, Cerambycidae, Lamiinae) without elitral carina of the Neotropical Region. New records and new species collected by inseticidal fogging in canopies in Ecuador are: Olivensa megacephala (Bates, 1866); Icupima laevipennis (Gahan, 1892); Hemilomecopterus alienus Galileo \& Martins, 2004; Acapiata gen. nov., type species $A$. dilatata sp. nov.; Acaiu gen. nov., type species $A$. spinosus sp. nov.; Okamira gen. nov., type species $O$. pulchra sp. nov. Two new spécies of Erana Bates, 1866 are also described: E. costaricensis sp. nov. from Costa Rica (Heredia) and E. flaviventris sp. nov. from Honduras (Yoro).
\end{abstract}

Keywords. Acaiu; Acapiata; Erana; insecticidal fogging; Okamira.

Resumo. Novos táxons de Hemilophini (Coleoptera, Cerambycidae, Lamiinae) sem carenas nos élitros da Região Neotropical. Novos registros e novas espécies de Hemilophini (Cerambycidae) coletados por pulverização de inseticida nas copas das árvores no Equador: Olivensa megacephala (Bates, 1866); Icupima laevipennis (Gahan, 1892); Hemilomecopterus alienus Galileo \& Martins, 2004; Acapiata gen. nov., espécie-tipo A. dilatata sp. nov.; Acaiu gen. nov., espécie-tipo $A$. spinosus sp. nov.; Okamira gen. nov., espécie-tipo $O$. pulchra sp. nov. Duas espécies novas de Erana Bates, 1866 também são descritas: E. costaricensis sp. nov. da Costa Rica (Heredia) e E. flaviventris sp. nov. de Honduras (Yoro).

Palavras-Chave. Acaiu; Acapiata; Erana; Okamira; pulverização de inseticida.

Baseados principalmente no Coleção F. T. Hovore, Santa Clarita, California (FTHC), fornecemos novas ocorrências e descrevemos novos táxons de Hemilophini sem carenas nos élitros. O material procedente do Equador foi coletado por T. L. Erwin (USNM) e colaboradores pelo método de pulverização de inseticida nas copas das árvores em um floresta de terra firme na Reserva Etnica Waoranic, Província de Napo, Equador.

Apenas recentemente, os Cerambycidae coletados por esse método nos foram enviados para estudo e revelaram quantidade apreciável de novos táxons. Tivemos acesso ao material coletado em Surumoni, Amazonas, Venezuela (Martins \& Galileo 2004b) onde os exemplares foram colecionados apenas sobre duas espécies de árvores.

Nesta contribuição descrevemos três novos gêneros e apresentamos novos registros para o Equador baseados em material coligido pelo método de pulverização de inseticidas em dosséis. As novas ocorrências são feitas para Hemilomecopterus alienus Martins \& Galileo, 2004, recentemente descrito da Colômbia amazônica; Icupima laevipennis, até o momento conhecida do Panamá e Olivensa megacephala com registros para a Amazônia oriental. Duas espécies novas de Erana Bates, 1866, de Honduras e da Costa Rica, são acrescidas às 27 espécies conhecidas.

As referências bibliográficas sob cada táxon restringemse à descrição original, às novas combinações e ao catálogo de Monné (1995) onde se encontram citações completas.

As siglas citadas no texto correspondem às seguintes coleções: BMNH, The Natural History Museum, London; FTHC, Coleção F. T. Hovore, Santa Clarita, California; INBio, Instituto Nacional de Biodiversidade, Santo Domingo de Heredia; RHTC, Coleção R. H. Turnbow, Fort Rucker, Alabama; MCNZ, Museu de Ciências Naturais, Fundação Zoobotânica do Rio Grande do Sul, Porto Alegre; MZSP, Museu de Zoologia, Universidade de São Paulo, São Paulo; USNM, National Museum of Natural History, Washington.

\section{Acapiata gen. nov.}

Etimologia Tupi, aka = chifre; pyatã $=$ forte, alusivo às antenas robustas. Gênero feminino.

\section{Espécie-tipo. Acapiata dilatata $\mathbf{s p . ~ n o v . ~}$}

Fronte levemente convexa, desarmada (fêmea), mais larga do que longa. Mandíbulas com ápice acuminado. Olhos não divididos. Lobos oculares superiores mais próximos entre si do que a largura de um lobo. Antenas com onze antenômeros, mais curtas que o corpo, alcançam aproximadamente o meio dos élitros. Escapo subcilíndrico, mais longo que o antenômero III. Flagelômeros engrossados; gradualmente menos espessos dos basais para os apicais. Antenômero III tão longo que o $\mathrm{IV}$; o IV mais longo que o V; os demais progressivamente mais curtos. Franja interna nos antenômeros basais constituída por pêlos longos e esparsos. Protórax mais largo do que longo; 
lados com uma gibosidade arredondada ao nível do meio. Pronoto sem tubérculos. Élitros sem carenas; margens laterais expandidas a partir do meio; extremidades arredondadas. Fêmures sublineares. Ápice dos metafêmures atingem a borda apical do urosternito II. Dente interno das garras tarsais pouco menor que o externo.

Discussão. Pelo escapo subigual em comprimento ao antenômero III, Acapiata gen. nov. assemelha-se a Apagomerella Gilmour, 1962 e Columbicella Galileo \& Martins, 1990. Acapiata gen. nov. distingue-se de Apagomerella pelas antenas curtas que atingem o meio dos élitros, pelo escapo curto cujo ápice apenas ultrapassa a orla anterior do protórax, pelos flagelômeros curtos e engrossados, pelo protórax mais largo do que longo e pelos élitros expandidos para a metade apical. Em Apagomerella, as antenas são mais longas que o corpo, o escapo atinge o meio do protórax, os flagelômeros são longos e delgados, o protórax é mais longo que largo e os élitros têm os lados paralelos. Separa-se de Columbicella pelas antenas mais curtas que o corpo, pelos antenômeros com comprimento decrescente a partir do IV e pelo protórax mais largo que longo. Em Columbicella, as antenas são pouco mais longas que o corpo, os antenômeros IV-VII têm comprimento crescente e o protórax é mais longo do que largo.

\section{Acapiata dilatata sp. nov.}

(Fig. 1)

Fronte e vértice avermelhados cobertos por pubescência amarelada; genas revestidas por pubescência branca; regiões atrás dos olhos pretas. Antenas pretas com a base de cada flagelômero avermelhada em pequena extensão. Centro do pronoto longitudinalmente avermelhado revestido por pubescência amarelada; lados com faixa tegumentar preta coberta por pubescência amarelada; pequena mancha glabra atrás do centro da faixa preta. Partes laterais do protórax com tegumento avermelhado recoberto por pubescência amarelada. Escutelo com pubescência amarelada. Metade anterior dos élitros amarelada com faixa preta longitudinal, junto à sutura, da base ao terço anterior; metade apical preta, separada da parte amarelada por linha irregular oblíqua em sentido descendente do dorso para a margem e para a sutura. Margens dos élitros com pêlos curtos abundantes. Face ventral preta, exceto mesosterno alaranjado. Fêmures anteriores e médios com a metade basal alaranjada e a metade apical preta no lado externo. Protíbias alaranjadas na face posterior.

Dimensões em mm. Comprimento total, 13,7; comprimento do protórax, 2,2; maior largura do protórax, 3,2; largura umeral, 3,7; largura do terço apical dos élitros, 4,2; comprimento do élitro, 10,5. Antenas: escapo, 1,6; antenômero III, 1,2; IV, 1,2; V, 1,0 .

Holótipo fêmea, EQUADOR, Napo: Reserva Etnica Waoranic $\left(00^{\circ} 39^{\prime} 10^{\prime \prime} \mathrm{S} 76^{\circ} 26^{\prime} \mathrm{W}, 1 \mathrm{~km}\right.$ sul de Onkone Gare Camp, $\left.220 \mathrm{~m}\right)$, 4.X.1994, T. L. Erwin et al. col. "inseticidal fogging of mostly bear green leaves, some with covering of lichenous or bryophytic plants in terre firm forest. At Trans. 1 Sta. 6, project MAXUS lote 855" (USNM).

\section{Acaiu gen. nov.}

Etimologia. Tupi, aka = chifre; iû ou yú = espinho. Alusivo ao espinho no antenômero III. Gênero masculino.

\section{Espécie-tipo, Acaiu spinosus sp. nov.}

Fronte sem projeção, abaulada. Olhos não divididos; lobos oculares superiores mais próximos entre si do que a largura de um lobo, com mais do que dez fileiras de omatídios. Antenas com onze antenômeros, mais longas que o corpo. Escapo levemente encurvado na base, atinge o quarto basal do pronoto. Antenômero III, ligeiramente curvo, com o dobro do comprimento do escapo; atinge o meio do élitro; com espinho apical curvo no lado dorsal; franja interna de pêlos longos, moderadamente densos. Antenômero IV com menos da metade do comprimento do III. Antenômeros V a XI com comprimentos gradualmente decrescentes. Protórax mais largo do que longo, sem gibosidades nos lados; pouco mais constrito na base do que no ápice. Élitros sem carenas; extremidades arredondadas. Fêmures lineares; ápice dos metafêmures atinge o meio do urosternito II. Garras tarsais com dente interno um quarto mais curto do que o dente externo.

Discussão. Acaiu gen. nov. separa-se de todos os gêneros conhecidos de Hemilophini por apresentar espinho curvo na extremidade dorsal do antenômero III. Além disso, Acaiu gen. nov. apresenta lobos oculares superiores mais próximos entre si e com mais de dez fileiras de omatídios.

\section{Acaiu spinosus sp. nov.}

(Fig. 2)

Cabeça com tegumento avermelhado coberta por densa pubescência amarelada. Escapo preto; o centro da parte interna amarelado. Pedicelo e estreita região basal do antenômero III amarelados. Antenômero III preto, com espinho apical alaranjado. Antenômero IV e base do V, alaranjados. Antenômeros VI e VII pretos com estreito anel basal amarelado; VIII-XI pretos. Protórax com tegumento alaranjado recoberto por densa pubescência amarelada. Tegumento elitral alaranjado nos três quartos anteriores e escuro no quinto apical; pubescência adensada junto à sutura e à margem externa, onde constitui faixas amareladas. Pernas alaranjadas, menos parte distal das tíbias, preta. Mesosterno e urosternitos enegrecidos. Mesepisterno, mesepimero e metepisterno recobertos por pubescência esbranquiçada densa.

Dimensões em mm. Comprimento total, 6,7; comprimento do protórax, 1,2; maior largura do protórax, 1,5; comprimento do élitro, 4,8; largura umeral, 1,9.

Holótipo macho, procedente do EQUADOR, Napo: Reserva Etnica Waoranic $\left(00^{\circ} 39^{\prime} 10^{\prime \prime S} 76^{\circ} 26^{\prime} \mathrm{W}, 1 \mathrm{~km}\right.$ sul de Onkone Gare Camp, Trans. Ent., 220 m), 4.X.1994, T. L. Erwin et al. col. "inseticidal fogging of mostly bear green leaves, some with covering of lichenous or bryophytic plants in terre firm forest. At Trans. 2 Sta. 1, project MAXUS lot 1411" (USNM) 


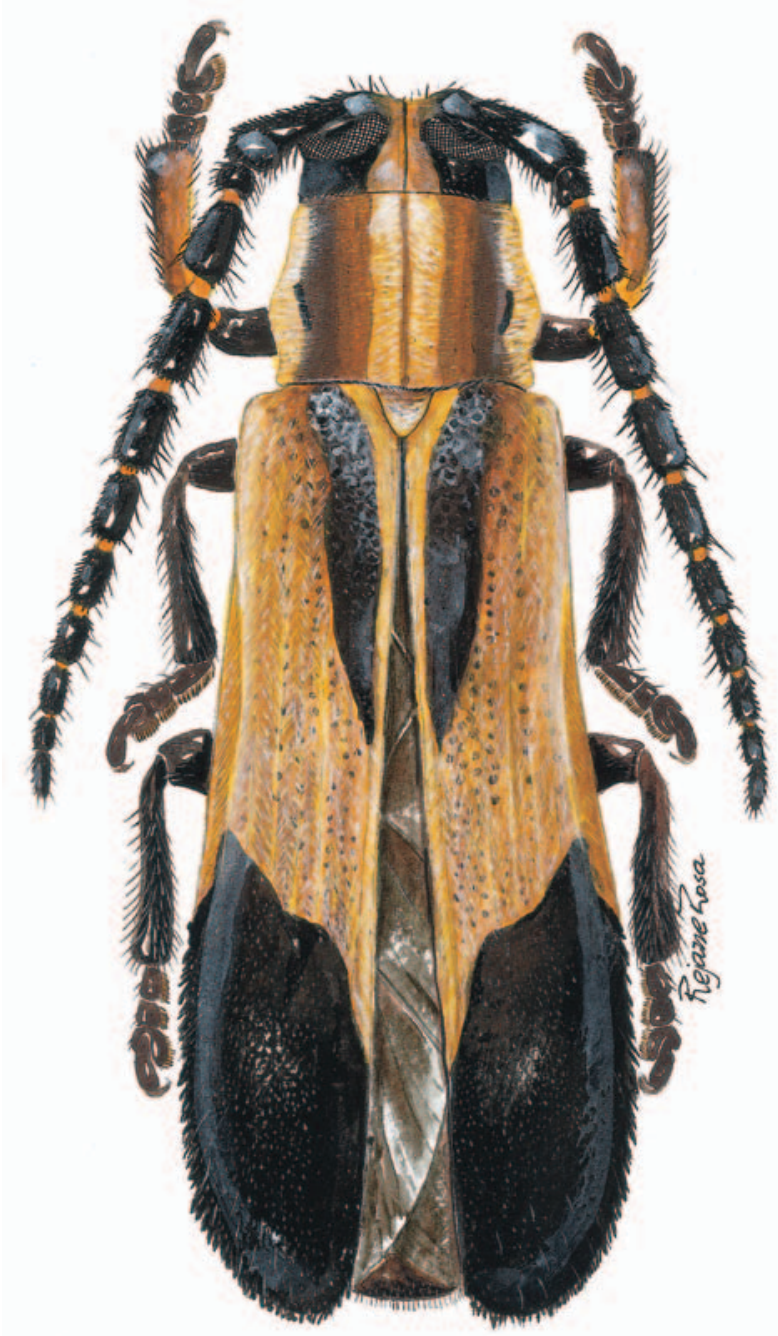

Fig. 1. Acapiata dilatata sp. nov., holótipo macho, Napo, Equador, comprimento $13,7 \mathrm{~mm}$.

\section{Okamira gen. nov.}

Etimologia. Tupi, oka = casa; mira = árvore; alusivo a habitante das árvores, pois os exemplares foram coletados nas copas pelo método de choque com inseticida. Gênero feminino.

\section{Espécie-tipo, Okamira pulchra sp. nov.}

Fronte plana, desarmada, mais larga do que longa. Mandíbulas com ápice acuminado. Olhos não divididos. Lobos oculares superiores mais próximos entre si do que a largura de um lobo. Antenas com onze antenômeros, mais curtas que o corpo, alcançam aproximadamente o meio dos élitros. Escapo subcilíndrico, tão longo quanto metade do antenômero III. Antenômero III e IV ligeiramente engrossados. Antenômero III tão ou mais longo que o dobro do comprimento do IV; o IV mais longo que o $\mathrm{V}$; os demais progressivamente mais curtos. Pêlos diferenciados no antenômero III e na metade basal do antenômero IV. Protórax mais largo do que longo; lados com uma gibosidade arredondada ao nível do terço basal. Pronoto sem tubérculos. Élitros com lados paralelos, sem carenas; extremidades arredondadas. Fêmures levemente fusiformes. Ápice dos metafêmures atingem o meio do urosternito II. Dente interno das garras tarsais pouco menor que o externo. Último urosternito profundamente emarginado.

Discussão. Okamira gen. nov. pertence a um pequeno grupo de gêneros sem carena e sem expansão lateral nos élitros: Dadoychus Chevrolat, 1833, Piratininga Galileo \& Martins, 1992 e Hemierana Aurivillius, 1923. Esses gêneros podem ser divididos em dois subgrupos, baseados no comprimento das antenas, tão ou mais longas do que o corpo (Dadoychus e Piratininga), ou mais curtas que o corpo (Hemierana e Okamira). Okamira gen. nov. distingue-se de Hemierana pelos lobos oculares superiores tão afastados entre si quanto a largura de um lobo; pelo antenômero III tão ou mais longo que o dobro do comprimento do IV e pela pilosidade do antenômero IV ocupando só a metade basal do artículo. Em Hemierana, gênero próprio à América do Norte, os lobos oculares superiores são tão afastados entre si quanto o sêxtuplo da largura de um lobo; os antenômeros III e IV são do mesmo comprimento e os pêlos longos cobrem todo antenômero IV.

\section{Okamira pulchra sp. nov}

(Fig. 3)

Macho. Fronte e genas cobertas por pubescência branca. Vértice e região atrás dos olhos, pretos. Antenas pretas menos anel no quarto apical do antenômero IV e na metade basal do antenômero V. Protórax com faixa centro-longitudinal larga, preta; lados cobertos por pubescência levemente rósea na face dorsal e branca para o lado do prosterno. Faixa longitudinal preta para o lado do prosterno. Élitros pubescentes com brilho levemente violáceo. Fêmures amarelados com largo anel central preto. Tíbias pretas com a base levemente mais clara. Tarsos pretos. Metepisternos e lados dos urosternitos cobertos por pubescência branca; restante da face ventral preta, fracamente pubescente.

Fêmea. Fronte acastanhada conforme a incidência da luz; genas cobertas por pubescência branca; mancha de pubescência rósea entre os tubérculos anteníferos e atrás dos olhos oculares. Lados e partes laterais do protórax cobertos por pubescência rosa-avermelhada. Fêmures amarelados com largo anel central preto. Tíbias pretas. Metepisternos, metasterno e urosternitos com pubescência escura, violácea conforme a incidência da luz. Lados dos urosternitos I-IV com pubescência branca e reflexos violáceos.

Dimensões em mm, macho/fêmea respectivamente. Comprimento total, 6,4/8,4-8,8; comprimento do protórax, 1,2/ 1,7-1,8; maior largura do protórax, 1,5/2,1-2,3; comprimento do élitro, 4,5/6,0-6,2; largura umeral, 1,8/2,4-2,8. Escapo, 1,3/1,31,5; antenômero III, 1,7/2,1-2,3; antenômero IV, 0,9/ 0,9-1,0. 
Holótipo macho, EQUADOR, Napo: Reserva Etnica Waoranic $\left(00^{\circ} 39^{\prime} 10^{\prime \prime} \mathrm{S} 76^{\circ} 26^{\prime} \mathrm{W}, 1 \mathrm{~km}\right.$ sul de Onkone Gare Camp, Trans. Ent., 220 m), 4.II.1996, Parátipo fêmea, mesmos dados do holótipo (USNM); parátipo fêmea, mesmos dados do holótipo, 4.X.1995, T. L. Erwin et al. col. "inseticidal fogging of mostly bear green leaves, some with covering of lichenous or bryophytic plants in terre firm forest. At Trans. 2 Sta. 1, project MAXUS lot 1181" (MZSP).

\section{Erana costaricensis sp. nov.} (Fig. 4)

Cabeça com tegumento vermelho-alaranjado; pubescência branca mais adensada na fronte e entre os tubérculos anteníferos. Lobos oculares superiores mais distantes entre si do que a largura de um lobo. Antenas atingem o ápice dos élitros na extremidade do antenômero V; antenômeros III e IV de cor variável: inteiramente pretos, ou pretos com ápice amarelado ou amarelados com base preta. Antenômeros V-VII amarelados. Antenômeros VIII-XI pretos. Antenômero III com pêlos longos no lado interno e pêlos menores no lado externo. Protórax castanho-escuro com lados avermelhados. Partes laterais do protórax com faixa de pubescência branca que se prolonga pelos mesepimeros, mesepisternos, metepisternos e lados dos urosternitos. Élitros castanhos com a metade basal mais avermelhada. Fêmures amarelados. Protíbias pretas no lado externo e amareladas no lado interno. Meso- e metatíbias pretas. Tarsômeros III-V alaranjados. Pro- e mesosterno alaranjados; metasterno castanho com área central mais alaranjada. Urosternitos alaranjados ou os basais mais escuros.

Dimensões em mm, macho. Comprimento total, 5,1-6,4; comprimento do protórax, 0,9-1,2; maior largura do protórax, 1,1-1,5; comprimento do élitro, 3,8-4,6; largura umeral, 1,5-2,0.

Holótipo macho, proveniente de COSTA RICA. Heredia: Estación Biológica La Selva (3 km S Puerto Viejo, $10^{\circ} 26^{\prime} \mathrm{N}, 84^{\circ} 01^{\prime} \mathrm{W}, 50-150$ m), 13.I.1999, INBio-OET col. (INBio). Parátipos - COSTA RICA, Heredia: Estación Biológica La Selva $\left(10^{\circ} 26^{\prime} \mathrm{N}, 84^{\circ} 01^{\prime} \mathrm{W}, 50-150\right.$ $\mathrm{m}$ ), macho, 30.VI.1995, INBio-OET (FTHC); ditto, macho, 1.VIII.1995, INBio-OET (INBio); ditto, macho, 31.V.1996, INBioOET (INBio). Mesmos dados, mas outro coletor, ditto, macho, 10.III.1980 H. A. Hespenheide col. (MCNZ); ditto, macho, 17.III.1980 (INBio); ditto, macho, 20.III.1980 (INBio); ditto, 2 machos, 24.III.1980 (INBio, MZSP); ditto, macho, 26.III.1980 (INBio); ditto, macho, 3.IV.1987 (MZSP); ditto macho, 9.IV.1988, (MCNZ); ditto, macho, 12.IV.1988 (INBio); ditto, macho, 9.V.1990 (FTHC). Limon: Amubri (70 m), macho III.1995, E. Rojas col. (FHTC); Setor Cocori (30 km N de Cariari, Finca E. Rojas, 100m), macho III.1994, E. Rojas col., L-N $286999567500 \# 2790$ (INBio); ditto, $150 \mathrm{~m}$, fêmea, 26.III24.IV.1992, F. A. Quesada col., L-N 286000_567500 (INBio).

Discussão. No gênero Erana, um dos mais numerosos da tribo, diversas espécies têm élitros pretos, mas em todas o pronoto preto apresenta faixa longitudinal de pubescência branca ao longo do meio ou toda metade anterior com pubescência branca. São raras as espécies que têm uma faixa longitudinal, estreita, a cada lado, de pubescência branca: $E$. cincticornis Bates, 1866, E. atatinga Galileo \& Martins, 1999, E. longiscapus (Bates, 1881), E. meyeri Martins \& Galileo. 1989. Erana costaricensis sp. nov., distingue-se de todas porque a faixa de pubescência branca localiza-se nos lados do protórax e não nos lados do pronoto. Além disso, $E$. costaricensis $\mathbf{s p . ~ n o v . ~ a p r e s e n t a ~ c a b e c ̧ a ~ a v e r m e l h a d a . ~}$

\section{Erana flaviventris sp. nov.}

(Fig. 5)

Cabeça pouco mais larga do que o protórax, preta com a porção inferior da fronte ou toda a fronte avermelhada. Mandíbulas alaranjadas com ápice preto. Lobos oculares superiores tão distantes entre si quanto o quádruplo da largura de um lobo. Lobos oculares inferiores salientes. Escapo preto. Antenômero III castanho-avermelhado com ápice preto. Antenômeros IV-VII amarelados; VIII-XI pretos. Pêlos no antenômero III em toda a superfície. Protórax amarelo-alaranjado destituído de faixas de pubescência branca. Escutelo amareloalaranjado. Élitros pretos. Pernas e toda a face ventral amareladas.

Dimensões em mm, respectivamente macho/fêmea. Comprimento total, 7,6/7,7-8,7; comprimento do protórax, 1,3/ 1,2-1,4; mais largura do protórax, 1,8/1,9-2,1; comprimento do élitro, 5,6/5,6-6,4; largura umeral, 2,3/2,3-2,6.

Holótipo macho procedente de HONDURAS, Yoro: P. N. Pico Pijol, 14.V.2002, R. H. Turnbow col. (RHTC). Parátipos: fêmea, mesmos dados do holótipo, (MZSP); fêmea, mesmos dados, mas coletada em 13.V.2002 (RHTC)

Discussão. Erana flaviventris sp. nov. assemelha-se à $E$. cendira Martins \& Galileo, 1993, ocorrente no Brasil (Mato Grosso), por apresentar protórax alaranjado e élitros pretos. $E$. flaviventris sp. nov. difere por apresentar a cabeça mais larga que o protórax, pelos antenômeros III (menos ápice) castanhoamarelado e IV até VII (menos o ápice) com tegumento amarelado e pelas pernas amareladas. Em E. cendira, a cabeça é mais estreita que o protórax, o antenômero III é preto (menos a base); o IV é bicolor, com a metade basal esbranquiçada e a apical preta; o V é esbranquiçado com o ápice preto e o VI é preto com a base esbranquiçada e o VII é preto; as meso- e metatíbias são pretas.

\section{Olivensa megacephala (Bates, 1866)}

Amphionycha megacephala Bates, 1866: 428.

Hemilophus megacephalus; Gemminger \& Harold, 1873: 3210 (cat.) Cephalodina megacephala; Bates, 1881: 213.

Olivensa megacephala; Martins \& Galileo, 1993: 172; Monné, 1995: 41 (cat.).

Bates (1866) descreveu O. megacephala do Brasil, Amazonas, Ega (atual Tefé). Martins \& Galileo (1993) mencionaram-na para Manaus, Amazonas. O material ora examinado amplia a distribuição para o Equador.

Material examinado. Equador, Napo: Reserva Etnica Waoranic $\left(00^{\circ} 39^{\prime} 10^{\prime \prime} \mathrm{S} 76^{\circ} 26^{\prime} \mathrm{W}, 1 \mathrm{~km}\right.$ sul de Onkone Gare Camp, Trans. Ent., 220 m), macho, 7.X.1994, T. L. Erwin et al. col. "inseticidal fogging of mostly bear green leaves, some with covering of lichenous or bryophytic plants in terre firm forest. At Trans. 8, Sta. 5, project MAXUS lot 904" (USNM). 



Figs. 2-5. 2, Acaiu spinosus sp. nov., holótipo macho, Napo, Equador, comprimento 6,7 mm; 3, Okamira pulchra sp. nov., holótipo macho, Napo, Equador, comprimento 6,4 mm; 4, Erana costaricensis sp. nov., Heredia, Costa Rica, comprimento 5,8 mm; 5, Erana flaviventris sp. nov., parátipo fêmea, Yoro, Honduras, comprimento $7,7 \mathrm{~mm}$.

Icupima laevipennis ( Gahan, 1892)

Lycidola laevipennis Gahan, 1892: 272, est. 12, fig. 1; Linsley, 1961: 634.

Icupima laevipennis; Martins \& Galileo, 1991: 563, fig. 9; Monné, 1995: 3 .
Acreditamos que este seja o primeiro exemplar conhecido da espécie após a descrição original. Linsley (1961) referiu-se à Icupima laevipennis como mimético de Lycidae (Coleoptera) e Martins \& Galileo (1991) reproduziram a figura do holótipo baseados no diapositivo realizado por J. S. Moure no BMNH. 
Material examinado. EQUADOR, Napo: Reserva Etnica Waoranic $\left(00^{\circ} 39^{\prime} 10^{\prime \prime} \mathrm{S} 76^{\circ} 26^{\prime} \mathrm{W}, 1 \mathrm{~km}\right.$ sul de Onkone Gare Camp, Trans. Ent., 220 m), fêmea, 8.II.1996, T. L. Erwin et al. col. "inseticidal fogging of mostly bear green leaves, some with covering of lichenous or bryophytic plants in terre firm forest. At Trans. 8, Sta. 9, project MAXUS lot $1479 "$ (USNM).

Hemilomecopterus alienus Martins \& Galileo, 2004

Hemilomecopterus alienus Martins \& Galileo, 2004a: 42, figs. 7, 8.

Espécie descrita recentemente da Colômbia, Amazonas: Parque Nacional Amacayacu (San Martin, $3^{\circ} 46^{\prime} \mathrm{S}, 70^{\circ} 18^{\prime} \mathrm{W}$ ).

Material examinado. EQUADOR, Napo: Reserva Etnica Waoranic $\left(00^{\circ} 39^{\prime} 10^{\prime \prime} \mathrm{S} 76^{\circ} 26^{\prime} \mathrm{W}, 1 \mathrm{~km}\right.$ sul de Onkone Gare Camp, Trans. Ent., 220 m), macho, 23.VI.1996, T. L. Erwin et al. col. "inseticidal fogging of mostly bear green leaves, some with covering of lichenous or bryophytic plants in terre firm forest. At Trans. 10, Sta. 8, project MAXUS lot 1618" (MZSP). Ditto, macho, 1.X.1996, At Trans. 4, St 2, lot 1692 (USNM).

Agradecimentos. A Frank T. Hovore, J. E. Wappes e R. H. Turnbow pelo empréstimo de material para estudo; à Rejane Rosa, Museu de Ciências Naturais, Fundação Zoobotânica do Rio Grande do Sul, pela execução das figuras.

\section{REFERÊNCIAS}

Bates, H. W. 1866. Contributions to an insect fauna of the Amazon Valley. Coleoptera: Longicornes. Annals and Magazin of Natural History 17: 425-435.

Bates, H. W. 1881. Biologia Centrali-Americana, Insecta, Coleoptera. London 5: 153-224, pls. 12-15.

Gahan, C. J. 1892. Additions to the Longicornia of Mexico and Central America, with notes on some previously-recorded species. Transactions of Entomological Society of London 1892: 255-274.

Gemminger, M. \& E. Harold. 1872. Catalogus Coleopterorum hucusque descriptorum synonymicus et systematicus. Monachii, Gummi. v. 9, p. 2669-2988.

Linsley, E. G. 1961. Lycidlike Cerambycidae (Coleoptera). Annals of the Entomological Society of America 54: 628-635.

Martins, U. R. \& M. H. M. Galileo. 1991. Subdivisão do gênero Lycidola Thomson, 1864 (Coleoptera, Cerambycidae, Lamiinae, Hemilophini). Revista Brasileira de Entomologia 35: 553 565 .

Martins, U. R. \& Galileo, M. H. M. 1993. Cerambycidae (Coleoptera) of the Canadian Museum of Nature, Ottawa. IV. Hemilophini (Lamiinae). Insecta Mundi 7: 169-173.

Martins, U. R. \& M. H. M. Galileo. 2004a. Contribuição aos Hemilophini (Cerambycidae, Lamiinae) da Colômbia e do Equador. Iheringia, Sér. Zool. 94: 37-44.

Martins, U. R. \& M. H. M. Galileo. 2004b. Cerambycidae (Coleoptera) coletados na Venezuela na copa de Matayba (Sapindaceae) e Vochysia (Vochysiaceae). Revista Brasileira de Entomologia 48: 229-232.

Monné, M. A. 1995. Catalogue of the Cerambycidae (Coleoptera) of the Western Hemisphere. Part XX. Subfamily Lamiinae: Tribes Hemilophini, Aerenicini, Pretiliini, Falsamblesthiini and Calliini. São Paulo, Sociedade Brasileira de Entomologia, 120 p. 